\title{
How Painful Can It Be? Rheumatic Diseases Through the Eyes of Future Nurses
}

\author{
Maria Do Céu Sá \\ Escola Superior de Enfermagem de Lisboa (ESEL), PhD Student, at \\ Universidade Católica Portuguesa (UCP), Lisboa, Portugal \\ Email: ceu.sa@esel.pt
}

\author{
Abílio Oliveira \\ Instituto Universitário de Lisboa (ISCTE-IUL), and Centro de Investigação em Sistemas e \\ Tecnologias de Informação Avançados (ADETTI-IUL), Lisboa, Portugal. \\ Author of several books (abiliooliveira.weebly.com) \\ Email: abilio.oliveira@iscte.pt
}

Doi:10.5901/mjss.2014.v5n13p275

\begin{abstract}
Rheumatic diseases, by their nature and symptoms are one of the diseases that have the greatest impact on public health, affecting thousands of people, and being directly responsible for serious limitations, not only on a physical level but also the emotional and social level. These diseases have a chronic nature. In many cases, they seriously influence the well-being of many people, as well as their productivity, and regular activity. They are associated with several problems, within the family or at a professional domain, forcing to major changes in the patients' routines, leading to situations of limitation, disability (temporary or permanent), absenteeism, impossibility to accomplish some tasks and duties, or early retirement. Nursing has an essential role on the prevention and management of chronic illnesses, giving healthcare and support to patients, in different stages of their illness. The aim of this study is to understand how students of nursing represent the situation and the problems of the patients affected by rheumatic diseases. We carried out a focus group with twelve students, three men and nine women with a mean age of 20 years, attending the 2nd year of the nursing program. On the interaction with the participants, we focused our attention on three questions: What is a rheumatic disease?; What are the implications of the disease for the person, and in his self-care?; How does rheumatic disease influences the image that a person has of himself? Future nurses consider that rheumatic disease has major consequences in people's lives, in their daily activities, work and family, pointing out that pain and bodily changes contribute to decreased self-esteem, lack of confidence and social isolation.
\end{abstract}

Keywords: Rheumatic disease, self-care, caring, nursing, pain, body.

\section{Introduction}

Rheumatic diseases generally have non-traumatic causes, and involve functional changes in the musculoskeletal system that can be potentially serious. Any rheumatic disease, regardless of its specific symptoms, emerge in a similar way, causing pain, difficulty or disability to perform various tasks, fatigue, and over time the disease can lead to deformations in the body, especially in the joints. Rheumatic diseases, by their nature and symptoms are one of the diseases that have the greatest impact on public health, affecting thousands of people, and being directly responsible for serious problems, not only on a physical level but also the emotional, familiar, professional and social level (e.g. Hill, 2006).

Many epidemiological studies classify the rheumatic diseases (RD) as the most frequent chronic diseases, those with greater economic and social impact on society, that motivate more medical consultations, and that cause higher spending on drugs (direct costs).

$\mathrm{RD}$ are the leading cause of medical certificates (both temporary as permanent), disability and requests for early retirement (indirect costs).

However, there are other consequences which may be more relevant about the real impact of $\mathrm{RD}$, which are the repercussions at the individual level (due to the pain and suffering associated with these diseases, and to functional difficulty and problems of moving around, which leads to reliance on other persons to perform various activities of life daily), social (including the relationship with family, friends and the community in general), professional (which may lead to absenteeism and early retirement) and economic (causing less gains, and more spending on medication, means of aid , etc.) (e.g. Lucas \& Monjardino, 2010).

Despite all the consequences that are known, we note a devaluation of $\mathrm{RD}$, since a long time, both by the general population, as health professionals and health authorities, mainly due to cultural issues, but also because these 
supposedly have a low impact in terms of mortality, and it is difficult to find statistical data and empirical studies that demonstrate unequivocally their impacts (Woolf \& Âkesson, 2001).

The RD may raise ideas of fatalism, misfortune and 'bad luck', and patients often state that 'there is nothing more to do', and 'we've got to stand the pain'. This misunderstanding and the lack of attention given to the RD contributes greatly to confusion generated between aging and rheumatic disease, often associating these two concepts interchangeably, contributing to the notion that the development of a rheumatic disease is inevitable, and there is no way to contradict it or fight it. Indeed, with age increase the changes of the musculoskeletal system and so increases the prevalence of rheumatic diseases. However, aging is not a disease, and not all changes that arise in the locomotion system are derived of a rheumatic disease.

A solution to this situation is not easy but is possible. An RD is not a burden or an inevitability to which a person is convicted, is indeed a huge challenge that demands adaptations and changes in daily life.

\section{Rheumatic Diseases and Nursing}

The RD can be prevented and the economic and social impacts can be mitigated. For such, the epidemiological and empirical evidences that highlight the relevance of RD should be disclosed, informing the population, in general, and investing on the training of health professionals, making them aware of these problems. It is also necessary to ensure a better accessibility of rheumatic patients to care and health centers. It is for this reason that Nursing Schools in Portugal have included in their curricula the fundamental theoretical aspects on rheumatic diseases, with the aim of training their students, alerting them and preparing them for this reality.

Nursing is a humanitarian and human science, which covers care of the persons, understood in the broadest sense of the promotion of life and everything that helps to live. The theory provides knowledge to improve practice by description, explanation, prediction and control of phenomena, and allows nurses to explain what they do, how they do it, and why they do it, thus helping to take better care of each person, increasing his autonomy and well-being (e.g., Adams, 1994; Bento, 1997; Kerouac et al, 1994). The nursing professors must realize that their role is not reduced to a mere transmission of knowledge, but its intervention in the teaching-learning process is of great importance in the construction and development of models, values and attitudes. It is essential that certain standards and values may be taught and experienced by students during their training course in conjunction with the science curriculum (Raya, 1990).

A large part of the knowledge, attitudes and values are learned in school. Recognizing our responsibility in training future nurses, and favoring an attitude of permanent interrogation on the practices of care, we tried to understand how nursing students represent the problems of patients with rheumatic diseases, in order to clarify its meaning and significance.

\section{Objective}

The global objective of this study is to understand how students of nursing represent the situation and the problems of the patients affected by rheumatic diseases.

\section{Method}

When we want to know and understand the significance and meaning of care, taking into account different points of view, or when we want to characterize how the individuals live their experiences, how they interpret their experiences and how themselves structure the social world in which they live, it is useful to use an interpretive methodology (eg Honoré, 2001; Bogdan and Biklen, 1994). The qualitative approach is useful and appropriate in this study, for allowing us to enter the symbolic universe of the representations of reumatic diseases among the students, and revealing the various facets of the subject under study.

A qualitative research methodology allows defining the phenomena according to the views of the persons depending on their attitudes and experiences, providing knowledge, understanding, and a careful and accurate interpretation, of the meaning and nature of past or current situations (Leinninger, 1985). The important thing is to select participants that allow in-depth study and may give us relevant information. There are no strict rules that define the sample size, but it should be intentionally small and diverse in order to highlight the good variety of individual experiences (Patton, 1990).

We carried out a focus group with twelve students, three men and nine women with a mean age of 20 years old, attending the 2nd year of the nursing program. As independent variables we considered gender/sex (men and women). 
On the interaction with the participants, we focused our attention on three questions (among other questions):

What is a rheumatic disease?

What are the implications of a rheumatic disease for a person/patient, and in his self-care?

How a rheumatic disease influences the image that a person has of himself?

The participants were informed that their participation in the study was anonymous, confidential and voluntary, respecting their privacy.

\section{Findings}

\subsection{What is a rheumatic disease?}

Thinking about meanings and definitions, most participants state that rheumatic diseases (RD) are chronic and degenerative diseases affecting the joints. Future nurses consider that RD are diseases that cause serious problems, discomfort and great suffering mainly due to the pain. The future nurses point out that pain is the leading cause of malaise. They point out that these diseases compromise the mobility of patients, causing them to lose agility, preventing them from leaving the house and perform numerous tasks of everyday life and increasing the risk of falls and other accidents.

\subsection{What are the implications of a rheumatic disease for a person/patient, and in his self-care?}

The responses to this question were diverse and showed various dimensions of the person. In terms of self-care, participants emphasize, in addition to difficulty walking, difficulties in performing household chores, personal hygiene, dressing and undressing in and even combing. These difficulties are due mainly to alterations in joint function but also to tiredness, fatigue and pain. Indeed, the physical limitations due to changes in joint function and functional disability may gradually lead to loss of independence of the individual, in particular for activities of daily living (e.g. Hill, 1999). Melanson and Downe-Wonboldt (2003) report that the mobility in general, either at home or in the community, journeys on foot or by transport, care of personal hygiene and household tasks can be very affected activities.

Students also note that patients have difficulty in entering the labor market, or in maintaining their regular professional activities, due to the prejudice associated with rheumatic diseases. These are often related with disability or incapacity, and many patients who are employed have to request an early retirement, in addition to having to spend more money on consultations, media support, travel, treatments and medications.

In social terms the participants relate mainly to isolation, of being put away from certain activities, tasks and from the others, and loneliness. At the family level, intimacy may be a problem and some problems may arise, because the sexual life may be compromised; particularly women find it difficult to play the role of wife, but also of mother or grandmother (Cardoso, 1996).

Given these diseases strongly affect the health and well-being; at an emotional level they are very associated with feelings of sadness, fear, insecurity, demotivation and revolt. Future nurses enhance that rheumatic diseases are more readily accepted by older people, because the oldest tend to think that they have already lived a long life, in comparison with the younger, and thus do not have as much to lose as younger patients have (the younger patients may also feel more limited by the constraints of the disease).

The psychological impact of rheumatic diseases is considered very negative by most authors, considering natural that with increasing age, every person will suffer from some kind of rheumatic problems. The pain and disability often cause anxiety, insecurity and depression. If we still add the problems of isolation in these situations, so common among older people, in our society, it is natural that their self-esteem and psychological condition be shaken (Gaião, 1990). Labour issues connected with the profession, and family issues, are interrelated and constitute factors associated with psychological changes or demands.

\subsection{How a rheumatic disease influences the image that a person has of himself?}

Students mentioned that diseases have implications especially for the body, and in the way patients look at themselves as persons. Some patients find that rheumatic disease is an evil of the body, which often leads them to hide themselves, hiding not only parts of their body, as well as hands. This situation gives rise to changes in self-image of the person, leading the patient to feel isolated and away from society, getting sadder, with low self-esteem, and sometimes feeling a strong revolt, in a state of anxiety and depression.

In young adults, the psycho-emotional aspects inherent to the situation of chronic disease may also generate 
various problems. Among young people, the changes on their body image, and the decrease of the exchange of affection between couples, can generate tremendous malaise. In fact, in any circumstance, context or situation, the body image is of vital importance for the understanding of the human psyche.

Body image refers to the body as subjective experience, considering the experiences and attitudes of each person in relation to his own body, and how it is organized. So, the body is an individual reality to the extent that we are in the world through our body, and it is with our body that we established relationships with others (and even with ourselves, of course). Rheumatic diseases are chronic, disabling and disfiguring diseases, thus they have a very significant impact on the body image. In turn, changes in body image affect our social interactions (e.g. Teixeira et al, 1986).

Our results are summarized on Table 1.

\section{Table 1}

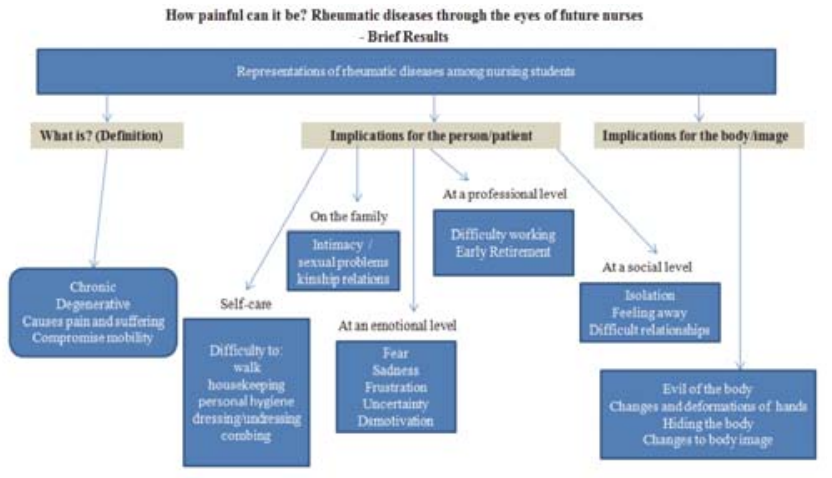

\section{Discussion and Conclusion}

We found that students consider that rheumatic diseases have strong implications for any patient at several levels: physical, psychological, emotional, family, professional and social. They generate and cause emotional and social problems related to pain, fear and insecurity, as well as they imply physical constraints of various kinds, and undermine the relationships between people, affecting their social interaction. Future nurses also reported that the decrease in capacity and even the loss of some skills, has influence at work, and can modify the work activity of the patients (as persons), in a way more or less markedly, with negative repercussions on all dimensions of human existence.

Since nursing is supported in caring the others, and being care a central aspect in the nursing profession, we can say that it is through the knowledge and techniques that we develop and assimilate, as ours, to integrate them in the most different domains and fields, that we build our knowledge and know-how (Honoré, 2001). In care, we experience what we are caring as an extension of ourselves and at the same time, as something separate from us that we respect for itself (Mayeroff, 1990).

Caring is helping the other to grow, without imposing our own direction. The main ingredients of care are knowledge, alternating rhythms, patience, honesty, trust, humility, hope and courage (Mayeroff, 1990). Adam (1983) reinforces this idea and states that without the attitude of deep respect of the nurses by the patients, as well as their ability to listen and understand, the knowledge would not be sufficient for nurses to provide the help of which the individual needs.

Nursing care aim, above all, at maintaining and improving the welfare, counseling the patients, helping them adopt the most appropriate behaviors in order to develop the ability to live, or trying to compensate for the harm caused to the functional limitations imposed by the disease, seeking to minimize any possible physical dysfunction, emotional, or social (Collière, 1989; Kérouac et al., 1995).

Regarding the way students talk about the problems of people with rheumatic diseases and how they articulate the elements/dimensions of representation, according to their abilities, we found three axes (or subcategories) that emerge around the concept of nursing: the scientific axis, the technical axis and the relational axis.

\subsection{The scientific axis}

To be nurse requires a great diversity of knowledge, to enlarge the heritage of knowledge in nursing (Collière, 1996). 
Students in this study also mentioned the importance of having in-depth knowledge about what is commonly practiced. To achieve change is necessary to have the intention to change, and this change can only happen in case we evaluate in a systematic way our practice, which leads to an improvement of nursing care and an increased knowledge (Basto, 1991). Future nurses emphasize that a good practical performance depends on a continued professional investment.

\subsection{The technical axis}

Beyond knowledge is also required for nurses to acquire competences or technical skills - the know-how. These usually arise from the diagnosis and prescription (direct care), in order to help treat patients. Caring integrates, inseparably, a relational and a technical dimension.

\subsection{The relational axis}

Philosophically, nursing suggests tenderness and a significant support to community, which gives it certain dynamic actions. Thus, the science of nursing is essentially a human science, where the person is studied as a whole. Nurse and patient are co-participants in a general process of health with increased responsibilities in the social, scientific and methodological fields (Watson, 1988). As a discipline, nursing is considered half art and half science, putting in this dichotomy an essential key link: knowledge, without which there would exist no culture or humanistic sense. What is required in addition to the skills or knowledge, are the moral and civic qualities, inherent to oneself (Carvalho 1996). Also, the participants in this study highlighted the importance of being with people and caring the patients with sensitivity and delivery.

Nursing must prepare professionals with a high level of competence, either in the scientific and technical field, as in relational and ethical realm. It is expected of the young students an open mind, a good ability to learn and transform their knowledge in the everyday practice, in relation with the users/patients and with their peers, so that, together, and in cooperation, they may be more prepared to contribute to the well-being of people.

There is thus a greater relevance to prepare these young people, with specific characteristics, and adapted to our contemporary society, always challenging, dynamic and diverse, in terms of culture, habits, practices and customs. No matter either the listing of content to be taught, but rather the process, the route and the interrelationships between what was and what can be. Thus the formation contributes to a form of social change, in which the individual power and authority should be phased out in favor of a true development of skills and reasoning (Gray 1984; Bowers 1987, cited by Watson, 1988).

Train competent professionals are not something that can be done in a place by itself. On the contrary, it is a process that is intertwined with the lives of people. What counts is to create training facilities, making available to trainees a repertoire of possibilities that allow them to better understand their work and improve their professional skills, reflect on their personal and social pathways, acquire knowledge and systematize information (Nóvoa, 1988, 1992).

As regards the strategies of teaching-learning, we recall that learning how to think is now regarded as a priority educational objective. Also in nursing has been a growing interest in exploring the ways of professional learning, particularly in the potential of reflection as a learning tool. Currently there is a recognized need to integrate theory into practice, being reflection an instrument that facilitates an inclusive learning. Basto (1994) argues that the way forward is to find ways of providing learning experiences where students have the opportunity to think about the practice, so that training influences the change and improvement of care.

Finally, we do not want to fail to mention that, we are aware that, in this study, we concentrated only on a portion of the problems involved in the care of patients with rheumatic diseases. There is still a long way to run.

\section{References}

Adam, E. (1983). Être Infirmière. Montreal: H. R. W.

Basto, M. L. (1998). Da intenção de mudar à mudança. Um caso de intervenção num grupo de enfermeiros. Lisboa: Rei dos Livros.

Bento, M. C. (1997). Cuidados e Formação em Enfermagem que Identidade? Lisboa: Fim de Século.

Bento, M. C. (1997). Enfermagem que Identidade. Lisboa: Fim de Século, 1997.

Bogdan, R. \& Biklen, S. (1994). Investigação Qualitativa em Educação: uma introdução à teoria e aos métodos. Porto: Porto Editora.

Cardoso, J. (2006). Sexualidade e Deficiência. Lisboa: Quarteto.

Carvalho, M.M.M. (1996). A Enfermagem e o Humanismo. Lisboa. Lusociência, 1996.

Cavaco, A. L. (2000). Olhar e ouvir o corpo. Pensar Enfermagem, 4(1), p. 41-46

Collière, M. F. (1989). Promover a vida - da prática das mulheres aos cuidados de enfermagem. Lisboa: Sindicato dos Enfermeiros 
Portugueses.

Hill, J. (1999). Rheumatology nursing. A creative approach. London: Churchill Livingstone.

Hill, J. (2006). Rheumatology nursing. A creative approach. 2nd edition. London: John Wiley \&Sons, Ltd.

Honoré, B. (2001). Persévérer ensemble dans l'existence. Paris: Seli Arslan.

Kérouac, S., Pepin, J.,Ducharme, F., Duquete, A., \& Major, F.,(1994). La Pensée enfermière. Quebec: Editions Ètudes Vivants.

Leinninger, M. M. (1985). Qualitative research methods in nursing. Orlando: Grune and Stratton Inc., 1985

Lucas, R. \& Monjardino, M. (2010). O estado da Reumatologia em Portugal. Porto: Observatório Nacional das Doenças Reumáticas.

Queirós, M. (2002). Reumatologia: clínica e terapêutica das doenças reumáticas, vol 2. Lisboa: Lidel.

Queirós, M. (2002). Reumatologia: fundamentos. Lisboa: Lidel.

Woolf A. \& A kesson, K. (2001). Understanding the burden of musculoskeletal conditions. The burden is huge and not reflected in national health priorities. British Medical Journal, 322, 1079-80.

Mayeroff, M. (1990). On caring. New York: Harper Perennial.

Melanson, P. \& Downe-Wamboldt, B. (2003). Confrontig life with rheumatoid arthritis. Journal of Advanced Nursing, Oxford, 42 (2), 124133.

Nóvoa, A. (1992). Os professores e a sua formação. Lisboa: Publicações Dom Quixote.

Nóvoa, A; Finger, M. (1988). O método (auto) biográfico e a formação. Lisboa: Departamento de Recursos Humanos.

Gaião, L. (1990). Impacto médico, económico e social dos reumatismos na 3aa Idade. Acta Reumatológica Portuguesa, 54, 1, 3-9.

Patton, M. Q. (1990). Qualitive evaluation and research methods. $2^{\mathrm{a}}$ ed. Newbury Park: Sage publications.

Raya, A. (1990). Can Knowledge be promoted and values ignored? Implications for nursing education. Journal of Advanced Nursing, 15, p.504-509.

Watson, J. (1988). Nursing: human science and human care - a theory of nursing. New York: National League for Nursing.

Teixeira, J. et al., (1986). A imagem do corpo e a representação de si em doentes com Artrite reumatóide. Revista Portuguesa de Reumatologia. Lisboa, 4, p. 205-212. 